\title{
Substantiation of the effective geotechnological parameters of activation heap leaching of gold from refractory ores
}

\author{
Anna Rasskazova ${ }^{1 *}$ and Paul Korpi ${ }^{2}$ \\ ${ }^{1}$ Mining Institute FEB RAS, 51 Turgenev st., Khabarovsk, 680000, Russia \\ ${ }^{2}$ IG Copper, 84628, Utah, Eureka, United States of America
}

\begin{abstract}
The difficulties associated with the hydrometallurgical processing of refractory ores and some methods of their solution are discussed in the article. Difficulties associated with leaching of goldcopper ores are characterized. Gold and copper content is $0.5 \mathrm{ppm}$ and 0.37 $\%$ respectively in the primary ores of the Malmyzh deposit. The ore is characterized as low grade. The geotechnology method of heap leaching is feasible for low grade ores processing. The characteristics of ore material favorable for heap leaching are listed in the paper. The current trends in ore preparation for heap leaching are briefly described. Hydrodynamic parameters of spraying are one of the important aspects influencing the process result. The hydrodynamic regimes implemented in the processes of heap leaching are listed and methods for determining the rational irrigation regime and the method of feeding the solution are given. Technological studies are required for any type of ore to assess the feasibility of heap leaching. Typically, technological studies begin with laboratory stage, then large-scale research are performed and the pilot-plant tests allows assessing the feasibility of the technology on the industrial scale. In this study, laboratory scale column leaching research were carried out. A method of activation chloride leaching with sulfuric acid-peroxide pre-oxidation was developed and tested. The leaching solutions were activated by the method of electro-photo-chemical activation with sequential electrolysis and ultraviolet irradiation. As a result of the experiment, 68-80\% copper recovery was achieved.
\end{abstract}

Keywords. Gold-copper ore, low grade ore, geotechnology, heap leaching, ore characteristics, ore preparation, hydrodynamic parameters, stages of technological research, reagent parameters, copper recovery.

\section{Introduction}

The technology for the extraction of precious metals from ores is based on the cyanide process; up to $90 \%$ of gold and a significant amount of silver are extracted by cyanide leaching. Category of refractory ores is presented by ores not amenable for cyanidation; cyanidation is either ineffective or characterized by low rates of metal recovery [1]. Refractory ores contain the gold not amenable to simple cyanidation alone, and low

\footnotetext{
* Corresponding author: annbot87@,mail.ru
} 
recoveries have resulted from metallurgical testwork. Increasingly common occurence is where the surface ore body is well oxidized and non-refractory and frequently overlays large tonnages of non-oxidized refractory ore. In these cases, the initial metallurgical operation will be conventional, with an 'add-on' refractory treatment process at a later stage [2].

Roasting and pressure oxidation are the most commonly used types of preparation of refractory mineral raw materials for hydrometallurgical processing. Biooxidation is also a promising method for the preparation of refractory ores and concentrates. In one of the leading research institutes of the Russian Federation, it is proposed to use ultrafine grinding to increase the efficiency of liberation of refractory geo-material [3].

The refractory ores and concentrates to the cyanide process is often connected with the association of gold with sulfide minerals, including iron [4].

Copper minerals are often found in ores; they are usually represented by metallic copper, copper (I) and (II) oxides, hydroxide, sulfate and basic carbonates (malachite, azurite). All of them are dissolved in cyanide solutions almost completely and rather quickly. Copper-glance $\mathrm{Cu}_{2} \mathrm{~S}$, covellite $\mathrm{CuS}$, bornite $\mathrm{Cu}_{5} \mathrm{FeS}_{4}$, enargite $\mathrm{Cu}_{3} \mathrm{AsS}_{4}$ and tetrahedrite $\mathrm{Cu}_{3} \mathrm{SbS}_{3}$, react with cyanide solutions, forming soluble compounds. These reactions usually cause increased reagent consumption and decrease gold recovery. The least reactive copper-bearing minerals for cyanide solutions are chalcopyrite $\mathrm{CuFeS}_{2}$ and chrysocolla $\mathrm{CuSiO}_{3} * \mathrm{H}_{2} \mathrm{O}$. Divalent copper causes the loss of cyanide due to its oxidation to cyanogen and cyanate, and monovalent copper makes free cyanide inaccessible for dissolution of gold due to the formation of complexes.

Gold-copper ores have iron impurities and contain iron in concentrations that make cyanidation technically possible, but economically ineffective. Oxidizing preparation for the processing of refractory gold-copper ore, containing iron impurities, is proposed. Oxidation is carried out with electro-photo-activated solutions [5].

The researched ore material is the primary ores of the Malmyzh deposit. It is characterized by $0.5 \mathrm{ppm}$ gold content and $0.37 \%$ copper content. According to the common classification, high-grade ores contain more than $2 \%$ copper, standard ores contain $1-2 \%$, low grade ores contain less than $1 \%$. The ores of the Malmyzh deposit are classified as low grade but are characterized by large reserves.

It is rational to consider the geotechnological method of heap leaching for processing of low grade ores [6].

\subsection{Process flow diagram of heap leaching}

The process flow diagram of heap leaching (HL) of gold-bearing ores and materials is quite simple and consists of the following operations:

- ore transportation;

- ore-preparation (crushing and/or agglomeration);

- preparation of heap leaching pad;

- construction of heap leaching pile;

- irrigation (leaching solution distribution) of a pile with a leaching solution;

- arrangement of ponds for collecting and storage of pregnant and barren (circulating) solutions;

- metal recovery cycle;

- environmental protection and disposal of the pile with reclamation of the heap leaching stockpile. 


\subsection{Favorable conditions for heap leaching}

The most favorable conditions for the organization of heap leaching gold by cyanidation are the conditions when the ore:

- effective cyanide leaching;

- contains extremely fine and flat gold particles;

- porous and permeable mineral medium;

- absence of carbonaceous or other constituents absorbing leached metal complexes;

- low contentment of not-target elements reacting with cyanide or interfere with the dissolution reaction;

- low portion of fine particles or clays that prevent uniform percolation of leaching solutions. Otherwise, preliminary agglomeration is required;

- absence or low content of acid-forming components that cause consumption of cyanide and alkali.

At present, in addition to jaw and cone crushing operations in ore preparation before heap leaching, there is a tendency to application of self-grinding processes. Roll crushers effectively increase the fracturing of ore material, which contributes to an increase in the permeability of the ore and the penetration of leaching solutions into the ore peace. Agglomeration of ore in ore preparation processes is necessary when ore contain big portion of fine particles it reduces percolation, cause the formation of channels and clogged zones inside the pile. Three parameters are important in pelletizing: the amount of binder added to the dry feed, the amount of water (or cyanide solution) added to the binder and ore mixture, and the curing time required to form and strengthen the pellets.

\subsection{Hydrodynamic parameters of heap leaching}

The hydrodynamic parameters of leaching are distinguished by the peculiarities of the percolation of the solution. There are four modes that are carried out in the process of heap leaching:

- filtration with a continuous flow of solutions (through pores, cracks and voids);

- infiltration, the main mode at heap leaching, characterized by the percolation of solutions as a discontinuous flow. Solutions wet or cover the mineral surfaces with a thin film;

- pulsating-static (percolation); changing stages of flooding of the mineral mass under the leaching solution, then solution drip;

- filtration-infiltration.

Taking into account that the mass transfer during leaching of useful components from lumpy material is mainly convective in nature, the flow of matter $\boldsymbol{J}$ transferred through a section of a heterogeneous medium with $1 \mathrm{~cm}^{2}$ area per unit time is determined by the equation:

where $\boldsymbol{J}_{f}$ - solution flow moved by fluid,

$$
J=J_{\mathrm{f}}+J_{d}=V C=D \operatorname{grad} C
$$

$\boldsymbol{J}_{\boldsymbol{d}}$ - solution flow moved by diffusion;

$\boldsymbol{V}$-speed of fluid movement;

$\boldsymbol{C}$ - concentration of solution (reagent or leached component);

$\boldsymbol{D}$ - diffusion coefficient (an area of external diffusion is defined at heap leaching).

It follows from the equation (1) that the most favorable conditions for leaching are achieved with constant movement of the solution, when there are maximum concentration gradients. In addition, the constant removal of the leached component and the addition of the leaching solution (necessary amount in the reaction zone), maintain high leaching rates. It plays the important role at the initial stage of the process (in the kinetic region and in the 
region of external diffusion). The least favorable condition is long-term standing of solutions, when the leaching rate constantly decreases due to a decrease in the concentration gradient ( $\operatorname{grad} \mathrm{C} \rightarrow 0$ ).

The infiltration regime is the most effective for coarse ore leaching among the hydrodynamic regimes adopted in practice. But pulsation-static scheme is recommended for high-clay or an ore with high fines content. Pulsation-static regime is organized by flooding the ore with a solution (upwards or downwards irrigation); standing under the leaching solution; discharge (drip) of the solution and repeating the cycles.

Another parameter that determines the leaching efficiency is the specific discharge of leaching solutions for irrigation. The generally accepted indicator, expressed in $l * m^{2} / h$, reflects only the hydrodynamic side of the process and does not take into account the amount of the supplied reagent. It does not characterize the process taking place in the volume of the ore mass. Therefore, it is proposed to use the indicator of the specific supply $\lambda$, expressed in $m^{3} / t$ or $l / t *$ day.

Numerous different-scale research have shown that an increase in the specific feed of solutions for leaching makes it possible to reduce the leaching time to planned extraction without increasing the specific consumption of the reagent and often the ratio $W: S$. Up to certain values, this dependence is linear. By increasing $\lambda$, the leaching time can be reduced by $50 \%$ or more.

To determine the rational specific supply of solutions, parallel experiments are carried out on ore (with optimal fraction), with the optimal solution concentration at different $\lambda$ values. Specific feed can vary from 0.01 to $0.1 \mathrm{~m}^{3} / \mathrm{t}^{*}$ day and above. Analyzing the leaching time and the specific consumption of the reagent, taking into account the concentration of gold in the drained solution, a rational value of $\lambda$ is established [7].

\subsection{Technological research}

Technological research is required for any type of ore to assess feasibility of heap leaching. Such a technological assessment of an ore sample for the conditions of heap leaching is still a long and expensive procedure. Techniques have been improved in recent years, it has reduced the time required to obtain the heap leaching parameters.

The amount of research required to determine the feasibility of the ore and optimize the heap leaching parameters depends on the type of ore, ore grade, deposit size, etc.

Before the start of technological testing, a detailed research program should be created. The research program should take into account all the parameters important for the development of a pilot-plant or industrial pile.

At present, the procedure and sequence of technological research of ores for the determination of heap leaching conditions are clearly defined. They usually involve three stages:

- laboratory (stirring leaching and on small column leaching);

- large-scale (large columns; leaching of different size fraction ores, or one sample with the optimal size fraction composition);

- pilot-plant (heap leaching process is performed on an experimental pile or in a very large column).

The choice of the hydrodynamic leaching regime and the determination of the rational irrigation regime and the method of solution irrigation are very important for all three stages of technological research. 


\section{Material}

According to the mineralogical and technological features, the primary ores of the Malmyzh deposit were divided into breccia and diorite-porphyrite types. Mineralogical analysis revealed chalcopyrite, pyrite, bornite, covellite, chalcocite in the samples of these ores; magnetite, sphalerite, and molybdenite are presented too. The main ore minerals are chalcopyrite and pyrite. The mineral forms are aggregate, with close mutual germination and disseminated. The main copper mineral is chalcopyrite.

The initial gold content in the ore of the diorite-porphyrite type is $0.5 \mathrm{ppm}$, silver is 1 ppm, copper is $0.37 \%$, iron is $4.83 \%$.

\section{Research methods}

In the present study, a pulsation-static (percolation) regime of ore irrigation was used. The following reagent scheme was tested:

1) Sulfuric acid-chloride scheme with nitric-sulfuric acid preoxidation.

Diffusion pre-oxidation with electro-photo-activated sulfuric acid-peroxide solution (50 $g / l+3 g / l)$ for 3 days.

Irrigation with sulfuric acid and sodium nitrite $(30 \mathrm{~g} / \mathrm{l}+3 \mathrm{~g} / \mathrm{l})$. Leaching with active hypochlorite-chloride solution was carried out then with acidification. When the acidity of leachate decreased, acidification with activated sulfuric acid solution was carried out.

A sample weight for laboratory tests is $500 \mathrm{~g}$. Sample is loaded into a percolation column (the ratio of $12 \mathrm{~cm}$ height to $6 \mathrm{~cm}$ diameter excluded the wall effect). The volumes of solutions used for irrigation, the volumes of discharges and their parameters (acidity, oxidation-reduction potential) are registered. Electro-activation of solutions is carried out by electrolysis and photo-activation is made by ultraviolet irradiation. Chemical analysis of pregnant solution is performed using atomic adsorption spectroscopy (Shimadzy AA-7000).

Method of preparation of leaching solutions:

1. Sulfuric acid-peroxide solution

The concentration of the acid is $1 \mathrm{~g} / \mathrm{l}$, the duration of electrolysis is $15 \mathrm{~min} / \mathrm{l}$, then acid is added up to $\mathrm{pH}=3$. Hydrogen peroxide $(32 \%)$ is introduced into the electro-activated solution of sulfuric acid in $1.5 \mathrm{~g} / 1$ amount. After that, the resulting solution is photoactivated $(5 \mathrm{~min} / \mathrm{l})$.

2. Chloride solution

Sodium chloride $(20 \mathrm{~g} / \mathrm{l} \mathrm{NaCl})$ is prepared, cooled down to $10{ }^{\circ} \mathrm{C}$ and bubbled by air for $30 \mathrm{~min}$. Electrolysis of solution lasts for $30 \mathrm{~min} / 1$. Solution is irradiated with a UV lamp for 7 minutes. Active chlorine content is determined by titration; $\mathrm{pH}$ and Eh are determined by a laboratory ionomer.

\section{Results and discussion}

The dynamics of copper extraction into a pregnant solution according to the sulfuricchloride scheme with nitrous-sulfuric acid preoxidation is shown in Fig. 1. 


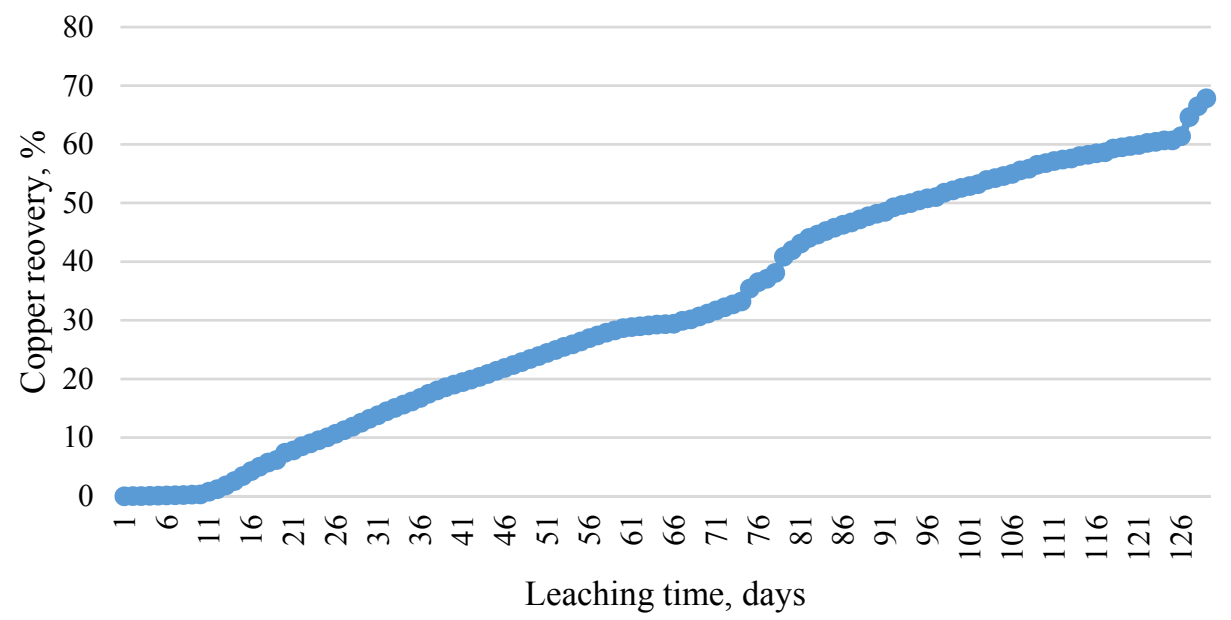

Fig. 1. Dynamics of copper recovery by cyanide free activation leaching

According to pregnant solution concentration and volume, $67.9 \%$ of copper extraction was obtained. Analysis of the solid leaching residue and initial copper contaent in ore provided $80.53 \%$ recovery rate. The duration of the experiment was 4.3 months (129 drains were made).

\section{Conclusions}

Laboratory column leaching of silver, gold and copper from the diorite-porphyrite type of primary ore of Malmyzh deposit was carried out on small-scale samples. The use of standard cyanide leaching of gold-copper ores is associated with a number of difficulties, including the high cyanide consumption for the formation of copper-cyanide complexes. Cyanide-free heap leaching is a feasible alternative to cyanide leaching. Malmyzh ore is low grade. Heap leaching method, which is simulated by column leaching in the laboratory, is a cost-effective solution to the problem of copper recovery. The primary ore of the Malmyzh deposit has good filtration properties. This is a favoring factor for percolation leaching. Ore agglomeration process and additional operating costs are not necessary. Malmyzh deposit has the huge reserves (1.3 billion tons of an ore, 5.156 million tons of copper and 278 gold tons), the economic effect of copper recovery from low grade ores can be very significant. Gold leaching tests should be carried out on larger and representative sample. Active chloride solutions are effective for gold leaching and high recovery result are expected. Research of leaching on larger samples and use of optimized modes is planned. High copper recovery $(68-80.5 \%)$ is achieved by cyanide-free electro-photoactivated leaching. Pre-oxidation of ore with sulfuric acid-peroxide solution and subsequent chloride leaching provided high rates of copper recovery from refractory gold-copper ores.

\section{Acknowledgment}

Chemical analysis of mineral raw material and leaching pregnant solutions was carried out on the basis of the Center for Collective Use of the Khabarovsk Federal Research Center FEB RAS. 


\section{References}

1. V.V. Lodeyschikov, Refractory gold and silver ores and problems of their rational use, https://zolotodb.ru/article/10465 (2011)

2. K.S. Fraser, R.H. Walton, J.A. Wells, Minerals Engineering, 4 (7-11), 1029-1041, (1991)

3. Recovery of gold and silver from technologically refractory ores and flotation concentrates http://www.irgiredmet.ru/activities/index.php?ID=637\&SID=96

4. V.V. Lodeyshchikov, Gold mining, 117, https://zolotodb.ru/article/1010 (2008)

5. A.G. Sekisov, A.V. Rasskazova, Patent RU No. 2647961, IPC C22B 11/00, 3/04 (2018)

6. V. Zh. Arens, Physical-chemical geotechnology (2010)

7. Fazlullin, Heap Leaching of Precious Metals, (Moscow, Publishing House of the Academy of Mining Sciences, 2001) 